\title{
Mechanisms of Compartmentalized Expression of Mrg Class G-Protein-Coupled Sensory Receptors
}

\author{
Yang Liu, ${ }^{1}$ Fu-Chia Yang, ${ }^{1}$ Tsukasa Okuda, ${ }^{2}$ Xinzhong Dong, ${ }^{3}$ Mark J. Zylka, ${ }^{4}$ Chih-Li Chen, ${ }^{5}$ David J. Anderson, ${ }^{6}$ \\ Rohini Kuner, ${ }^{7}$ and Qiufu Ma ${ }^{1}$ \\ ${ }^{1}$ Dana-Farber Cancer Institute and Department of Neurobiology, Harvard Medical School, Boston, Massachusetts 02115, ${ }^{2}$ Department of Biochemistry and \\ Molecular Biology, Kyoto Prefectural University of Medicine, Kawaramachi-Hirokoji, Kamigyo-ku, Kyoto 602-8566, Japan, ${ }^{3}$ Department of Neuroscience, \\ The Johns Hopkins University School of Medicine, Baltimore, Maryland 21205, ${ }^{4}$ Department of Cell and Molecular Physiology, University of North Carolina \\ School of Medicine, Chapel Hill, North Carolina 27599, ${ }^{5}$ School of Medicine, Fu-Jen Catholic University, Taipei 24205, Taiwan, ${ }^{6}$ Division of Biology and \\ Howard Hughes Medical Institute, California Institute of Technology, Pasadena, California 91125, and ${ }^{7}$ Department of Molecular Pharmacology, \\ Pharmacology Institute, University of Heidelberg, Heidelberg 69120, Germany
}

Mrg class G-protein-coupled receptors (GPCRs) are expressed exclusively in sensory neurons in the trigeminal and dorsal root ganglia. Pharmacological activation of Mrg proteins is capable of modulating sensory neuron activities and elicits nociceptive effects. In this study, we illustrate a control mechanism that allows the Runx1 runt domain transcription factor to generate compartmentalized expression of these sensory GPCRs. Expression of $\mathrm{MrgA}, \mathrm{MrgB}$, and $\mathrm{MrgC}$ subclasses is confined to an " $\mathrm{A} / \mathrm{B} / \mathrm{C}$ " neuronal compartment that expresses Runx1 transiently (or does not express Runx1), whereas MrgD expression is restricted to a " $D$ " compartment with persistent Runxl expression. Runx 1 is initially required for the expression of all $\mathrm{Mrg}$ genes. However, during late development Runx1 becomes a repressor for $M r g A / B / C$ genes. As a result, $M r g A / B / C$ expression persists only in the Runx1 ${ }^{-}$"A/B/C" compartment. In $\Delta 446$ mice, in which Runx1 lacks the C-terminal repression domain, expression of $M r g A / B / C$ genes is dramatically expanded into the Runx1 " $D$ " compartment. MrgD expression, however, is resistant to Runx1-mediated repression in the " $\mathrm{D}$ " compartment. Therefore, the creation of Runx $^{+}$and Runx $1^{-}$compartments, in conjunction with different responses of $\mathrm{Mrg}$ genes to Runx1-mediated repression, results in the compartmentalized expression of $M r g A / B / C$ versus $M r g D$ genes. Within the $M r g A / B / C$ compartment, $M r g B 4$-expressing neurons innervate exclusively the hairy skin. Here we found that $S \mathrm{mad} 4$, a downstream component of bone morphological protein-mediated signaling, is required selectively for the expression of $\mathrm{MrgB4}$. Our study suggests a new line of evidence that specification of sensory subtypes is established progressively during perinatal and postnatal development.

Key words: Runx1; nociceptors; Mrg class G-protein-coupled receptors; nociceptive ion channels and receptors; cell type specification; dorsal root ganglia

\section{Introduction}

The mouse genome encodes $50 \mathrm{Mrg}$ (also named Mrgpr/SNSR) class G-protein-coupled receptors (GPCRs), 12 of which are expressed exclusively in the somatic sensory neurons located in the trigeminal ganglia and dorsal root ganglia (DRG) (Dong et al., 2001; Lembo et al., 2002; Choi and Lahn, 2003; Zylka et al., 2003; Zhang et al., 2005; Burstein et al., 2006). These $\mathrm{Mrg}$ genes are divided into four subclasses: A (MrgA1-A8), B (MrgB4 and B5), C (MrgC11), and D (MrgD) (Zylka et al., 2003; Zhang et al., 2005).

Received June 5, 2007; revised Nov. 9, 2007; accepted Nov. 14, 2007.

The work was supported by National Institutes of Health (NIH)-National Institute of Neurological Disorders and Stroke Training Grant 5T32NS007473-09 (F.-C.Y.), NIH-National Institute of Dental and Craniofacial Research Grant 1R01DE018025 (Q.M.), and NIH-National Institute of Neurological Disorders and Stroke Grant 5P01NS047572 (Q.M.). Q.M. is a Claudia Adams Barr Scholar. We thank Drs. Gary Gilliland and Nancy Speck for the Runx 1 conditional knock-out mice, Chuxia Deng for conditional Smad4 null mice, David Rowitch for Wnt1-Cre mice, Tom Jessell for the Runx1 antibody, and Keith Ligon for critical comments on this manuscript.

Correspondence should be addressed to Qiufu Ma, Dana-Farber Cancer Institute, 1 Jimmy Fund Way, Boston, MA 02115. E-mail: qiufu_ma@dfci.harvard.edu.

DOI:10.1523/JNEUROSCI.4472-07.2008

Copyright $\odot 2008$ Society for Neuroscience $\quad$ 0270-6474/08/280125-08\$15.00/0
In adult mice, these $\mathrm{Mrg}$ subclasses exhibit compartmentalized expression, as indicated by the nonoverlapping expression of MrgD with other Mrg genes (Dong et al., 2001; Zylka et al., 2003, 2005) (see below). Most interestingly, $\mathrm{MrgD}^{+}$and $\mathrm{MrgB4}^{+}$neurons innervate distinct peripheral targets, skin epidermis and the hairy skin, respectively (Zylka et al., 2005; Liu et al., 2007). Pharmacological activation of Mrg proteins is able to modulate neuronal activities and evoke painful responses (Grazzini et al., 2004; Cai et al., 2007; Crozier et al., 2007). However, how compartmentalized expression of $\mathrm{Mrg}$ genes is established during development is poorly understood.

A series of recent studies has shown that the runt domain transcription factor Runx1 plays a pivotal role in controlling the development of sensory neurons, particularly those involved with nociception (Theriault et al., 2005; Chen et al., 2006; Kramer et al., 2006; Marmigere et al., 2006; Zhong et al., 2006; Woolf and Ma, 2007; Yoshikawa et al., 2007). Runx1 is initially expressed in most nociceptors (Levanon et al., 2002; Chen et al., 2006). Subsequently, Runx1 expression is extinguished in most peptidergic nociceptors (Chen et al., 2006), and persists primarily in nonpep- 
tidergic nociceptors (Chen et al., 2006; Kramer et al., 2006). Genetic studies demonstrate that Runx1 is required for the expression of nearly two-dozen ion channels and receptors, including the whole family of Mrg genes (Chen et al., 2006) (see Fig. 1).

In this study, we will illustrate a control mechanism that allows Runx1 to establish compartmentalized expression for Mrg class sensory GPCRs. Accordingly, expression of $\mathrm{MrgA}, \mathrm{MrgB}$, and $M r g C$ subclasses is confined to an " $\mathrm{A} / \mathrm{B} / \mathrm{C}$ " neuronal compartment that expresses Runx1 transiently (or does not express Runx1), whereas MrgD expression is restricted to a " $D$ " compartment with persistent Runxl expression.

\section{Materials and Methods}

Animals. The generation of Runx1 conditional mutant mice, Wnt1-Cre transgenic mice, $\Delta 446$ mice, Smad4 conditional null mice, $M r g D$-GFP mice and SNS-Cre transgenic mice has been described previously (Jiang et al., 2000; Yang et al., 2002; Agarwal et al., 2004; Nishimura et al., 2004; Growney et al., 2005; Zylka et al., 2005). The morning that vaginal plugs were observed was considered as E0.5. PCR-based genotyping for conditional null mice has been described previously (Chen et al., 2006). The following primers were used for the $\mathrm{MrgD}$-GFP mutant allele, 5'-ATG GTG AGC AAG GGC GAG GAG-3' and 5' -TCG CGC TTC TCG TTG GGG TCT TTG-3'; for the $M r g D$-GFP wild-type allele, 5' -ATG AAC TCC ACT CTT GAC AG- $3^{\prime}$ and $5^{\prime}$-CAC TGG TGT TTG TTG GGA TG-3' ${ }^{\prime}$; for the $\Delta 446$ mutant allele, $5^{\prime}$-TCG CTT TCA AGG TGG TGG CA-3' and 5'-TCC GGA GCC GTT GAG AGT C-3'; and for the wildtype Runx 1 allele, 5' -TGT CTC TGC ATC GCA GGA CT-3' and 5' -TGT GCG TTC CAA GTC AGT TGT-3'.

In situ hybridization and immunostaining. The in situ hybridization (ISH) procedure and the probes used in this study have been described previously (Chen et al., 2006). For ISH combined with anti-GFP fluorescent immunostaining, GFP was detected before the ISH procedure. Frozen sections were dried at room temperature for $10 \mathrm{~min}$, postfixed in $4 \%$ paraformaldehyde for $15 \mathrm{~min}$, washed 3 times with PBS for $5 \mathrm{~min}$ each, incubated with anti-GFP primary antibody (1:500 in PBT; Invitrogen, Carlsbad, CA) for 30 min, washed three times with PBS for 5 min each, and incubated with Alexa-488-conjugated secondary antibody (1:200 in PBT; Invitrogen) for $30 \mathrm{~min}$. Note that all solutions were prepared under RNase-free conditions. To avoid the masking of fluorescent signal by the subsequent ISH dye signal, all sections were photographed by fluorescence microscopy, followed by regular ISH procedure using an alkaline phosphatase (AP)-conjugated antibody (1:2000; Roche, Indianapolis, IN) and 5-bromo-4-chloro-indolyl-phosphate/nitroblue-tetrazolium (BCIP/NBT) substrates for development. The bright-field images of opaque in situ signals were inverted into pseudo-fluorescent images, and then merged with GFP fluorescent images.

ISH combined with anti-Runx1 (from Dr. Thomas Jessell, Columbia University, New York, NY) or IB4 fluorescent staining has been described previously (Chen et al., 2006), with the following modification. Fluorescent signals of Runx1 and IB4 were photographed first, followed by color development of ISH signals with BCIP/NBT substrates. The bright-field images of ISH signals were inverted and then merged with fluorescent images. As noted above, this sequential photographing avoids the masking of low-level fluorescent signals by nonfluorescent ISH signals, leading to a more sensitive detection of the coexpression of Runxl or IB4 with genes of interest. For example, in this study, we were able to detect high or medium levels of Runxl protein in virtually all $\mathrm{MrgD}^{+}$cells, whereas the previous procedure (in which ISH signals developed first, followed by Runx1 immunostaining) failed to show medium levels of Runxl expression in a fraction of $\mathrm{MrgD}^{+}$neurons (Chen et al., 2006).

For double color ISH, two probes were labeled with fluorescein- or digoxigenin-UTP. The probes were detected with peroxidase (POD)conjugated anti-digoxigenin antibody (1:400; Roche) and APconjugated anti-fluorescein antibody (1:1000; Roche). The fluorescent signal development for POD consists of three sequential amplification steps: (1) TSA Biotin System (1:100; PerkinElmer, Wellesley, MA), (2) Vectastain ABC Kit (Vector Laboratories, Burlingame, CA), and (3) TSA
Fluorescein System (1:50; PerkinElmer). The fluorescent signals were photographed, followed by development for AP with BCIP/NBT substrates. The bright-field images of nontransparent purple signals were inverted, and then merged with fluorescent images. Because the signal of the second probe was developed with nonfluorescent BCIP/NBT substrates, this modified double color ISH procedure is more sensitive than the procedure that involves fluorescent substrates for both probes (Dong et al., 2001; Zylka et al., 2003). For example, the colocalization of MrgA3 and $M r g B 4$ shown in this study was not detected in the previous study (Zylka et al., 2003).

Cell counting. To compare total DRG neurons, T12 thoracic and L4/L5 lumbar DRG were dissected from three pairs of mutant and control mice, fixed, embedded, sectioned at $12 \mu \mathrm{m}$ thickness. One of six adjacent sets of sections was hybridized with the pan-neuronal probe SCG10, and the number of $S C G 10^{+}$neurons was counted. Only cells containing nuclei were counted. To determine the percentages of neurons expressing molecular markers, six adjacent sets of sections were prepared from each T12 DRG and probed separately with six different probes, one of which was the pan-neuronal marker SCG10 so that percentages of DRG neurons expressing a gene can be calculated. Four or more independent T12 DRG or L4/L5 lumbar DRG were used for each counting. The difference between wild-type and mutant samples was subjected to a Student's $t$ test, with $p<0.05$ considered significant.

\section{Results}

\section{Loss of Mrg gene expression in conditional Runx1 null mutants}

We recently reported that Runxl is necessary for the expression of two Mrg subclasses, class B (MrgB4 and MrgB5) and class D $(\mathrm{MrgD})$ (Chen et al., 2006). To determine whether Runx1 controls the expression of class A $(M r g A 1-A 8)$ and class C $(\mathrm{MrgC11})$ genes, we analyzed Runx1 conditional knock-out mice by crossing floxed Runx1 mice $\left(R u n x 1^{F}\right)$ with Wnt1-Cre transgenic mice (Jiang et al., 2000; Growney et al., 2005). We have previously reported that in $R u n x 1^{F / F} ;$ Wnt1-Cre mice [referred here to as Runx $\left.1^{-/-}(W n t 1)\right]$, Runx1 is removed in sensory precursors, therefore representing a complete null mutation in nociceptors (Chen et al., 2006). We found that expression of MrgA1-A8 was eliminated in $R u n x 1^{-/-}(W n t 1)$ mice at every stage examined, from embryonic day 16.5 (E16.5) to postnatal day 30 (P30) (Fig. $1 A-F)$ (data not shown). High levels of $\mathrm{MrgC11}$ expression were also eliminated in adult $R_{u n x 1^{-/-}}(W n t 1)$ mice (Fig. $1 H$ vs $G$, arrow), but low levels of expression were independent of Runx1 (Fig. $1 H$ vs $G$, arrowheads). We have previously shown that neuronal survival is not affected in $R u n \times 1^{-/-}($Wnt1) mice (Chen et al., 2006). Therefore, the loss of $M r g$ gene expression is unlikely to be caused by a loss of neuronal cells. Altogether, these data imply a requirement of Runx1 for the expression of all $\mathrm{Mrg}$ class GPCR genes.

\section{Compartmental expression of $\mathrm{Mrg}$ genes in adult DRG}

To understand how Mrg gene expression is regulated, we examined in detail the cellular compartments that express $\mathrm{Mrg}$ subclasses by using double color in situ hybridizations. As reported previously, adult $\mathrm{MrgD}^{+}$neurons did not coexpress $\mathrm{MrgA3}$ (Fig. 2A) or MrgB4 (Fig. 2 B) (Dong et al., 2001; Zylka et al., 2005). Here we found that the expression of two class $A$ members, $M r g A 3$ and $M r g A 4$, overlapped extensively with each other (Fig. $2 C$, arrows). Expression of $M r g B 4$ was confined to neurons that exhibited a low level of $M r g A 3$ (Fig. 2D, arrows); neurons with elevated MrgA3 expression did not coexpress MrgB4 (Fig. 2D, arrowheads). It was reported that in adult DRG, elevated $\mathrm{MrgC11}$ expression is excluded from $\mathrm{MrgD}^{+}$neurons (also see Fig. $3 \mathrm{C}$ ), but overlaps with $\mathrm{MrgA3}^{+}$neurons (Zylka et al., 2005). Consistent with the restriction of $M r g B 4$ expression to a subset of 


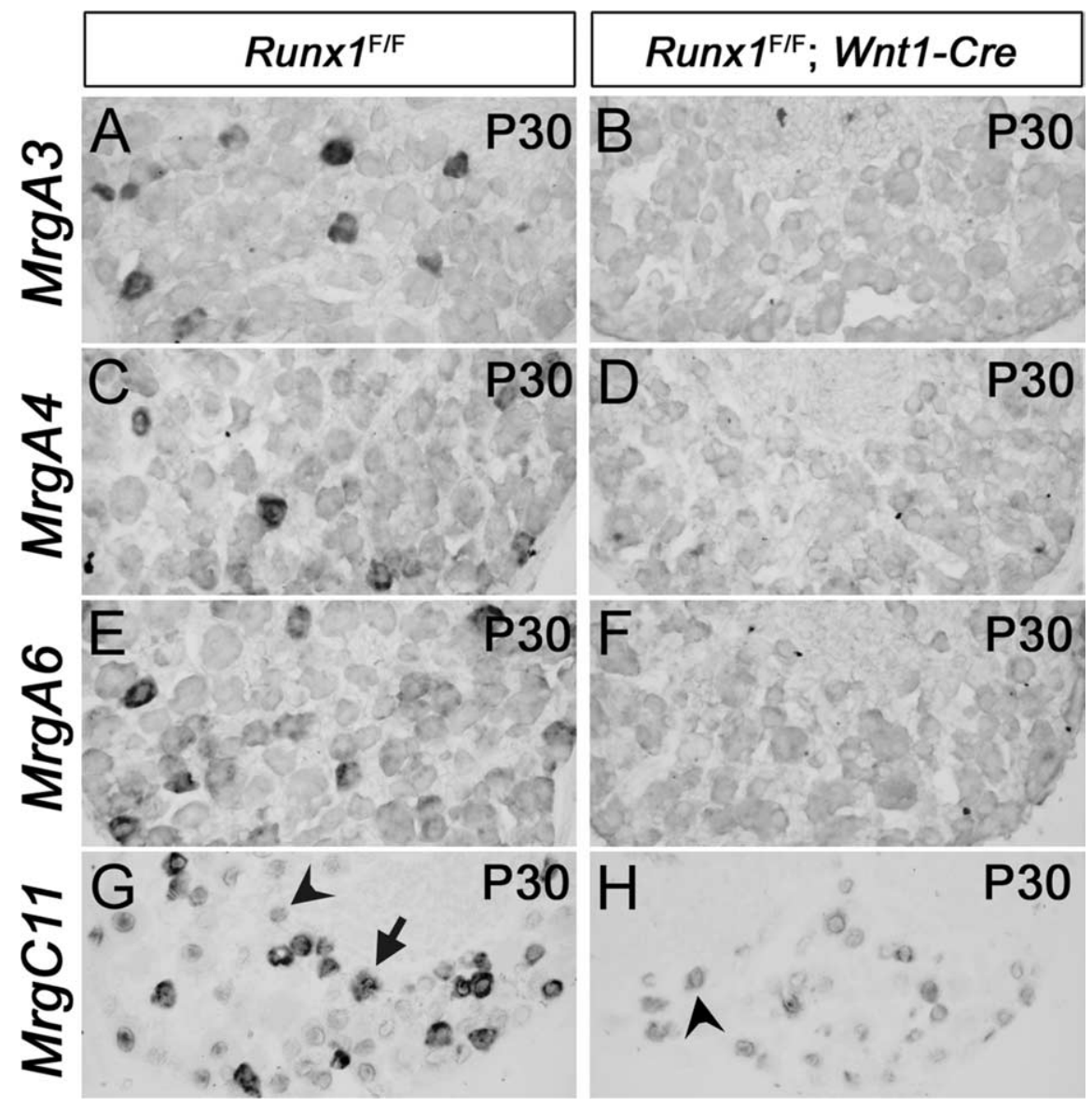

Figure 1. Loss of Mrg gene expression in Runx $1^{\mathrm{F} / \mathrm{F}}$; Wnt1-Cre mice [mentioned as Runx $1^{-/-}$(Wnt1) mice in text]. In situ hybridizations with indicated Mrg probes were performed on sections through P30 T12 thoracic DRG.

$\operatorname{MrgC11}$ (Fig. 3B). We also found that at P2 and P4, GFP protein was detected in $79.4 \%$ (131 of 165 ) and $82.3 \%$ (51 of 62) of $\mathrm{MrgA3}^{+}$and $\mathrm{MrgB4}^{+}$neurons, respectively (Fig. 3D, F, arrows). Because adult $\mathrm{MrgA3}^{+}$and $\mathrm{MrgB}^{+}$neurons coexpress MrgC11 (Fig. 2), we concluded that most $\mathrm{Mrg}^{+}$neurons at early developmental stages coexpress $M r g D$ and $M r g C 11$. By P30, GFP protein, however, can no longer be detected in $\mathrm{MrgA3}^{+}, \mathrm{MrgB}^{+}$or $\mathrm{MrgCl1}^{+}$neurons in $\mathrm{MrgD} \mathrm{GFP/+}^{\mathrm{G}}$ heterozygous mice (Fig. 3C,E, $G$ ). These data suggest that the "D" compartment retains $\mathrm{MrgD}$ expression and extinguishes $\mathrm{MrgC11}$ expression, and the "A/B/C" compartment retains $\mathrm{MrgC11}$ expression, extinguishes $M r g D$ expression, and acquires the expression of $M r g A$ and $M r g B$ genes (summarized in Fig. $3 H$ ).

\section{Dynamic Runx1 expression marks two Mrg expression compartments}

To gain insights into how Runxl regulates Mrg genes, we examined Runxl expression in $\mathrm{Mrg}^{+}$neurons at multiple developmental stages. Expression of $\mathrm{MrgD}$ was confined predominantly to Runx1 ${ }^{+}$neurons, from P7 to P30 (Fig. 4A,B). Unexpectedly, despite the loss of expression of $M r g A 3$ and MrgB4 in Runx1 ${ }^{-/}$(Wnt1) mice, Runx1 protein was not detected in $\mathrm{MrgA3}^{+}$or $\mathrm{MrgB}^{+}$neurons at neonatal and adult stages, including P2 and P4 when the expression of these two genes is actively be-

$\mathrm{MrgA3}^{+}$neurons, $\mathrm{MrgB} 4$ was expressed in a subset of $\mathrm{MrgCl1}^{+}$ neurons (Fig. $2 E$, arrows). Previous studies failed to detect a coexpression of MrgB4 with MrgA3 or MrgC11 (Zylka et al., 2005); the discrepancy may be attributable to a difference in sensitivity between using nonfluorescent substrates and fluorescent substrates (see Materials and Methods)

In summary, neurons expressing $M r g$ genes in adult DRG can be divided into two compartments: the " $\mathrm{D}$ " compartment that expresses $M r g D$ and the "A/B/C" compartment that shows a partially overlapping expression of $\operatorname{MrgA}, \operatorname{MrgB}$, and $\operatorname{MrgC}$ genes (Fig. $2 F$ ).

\section{Progressive segregation of $\mathrm{Mrg}$ expression compartments}

We next asked when the segregation of the "A/B/C" and " $D$ " neuronal compartments emerges, by examining their expression at early developmental stages. We found that robust expression of $\mathrm{MrgC11}$ and $\mathrm{MrgD}$ was already detected at E16.5, whereas expression of $M r g A 3$ and $M r g B 4$ was initiated at P0 and P2, respectively (Fig. 3A). To further examine the relationship among $\mathrm{Mrg}^{+}$neurons, we performed a transient fate-mapping experiment by using the $M r g D^{G F P}$ knock-in mice, in which the $M r g D$ coding region is replaced by the gene for green fluorescent protein (GFP) (Zylka et al., 2005). In adult $M r g D^{G F P /+}$ heterozygous mice, double staining detected a complete overlap between GFP and $M r g D$ mRNA, suggesting that GFP expression can be used to faithfully mark $\mathrm{MrgD}^{+}$neurons (Zylka et al., 2005) (data not shown).

In P2 $\mathrm{MrgD} \mathrm{GFP/+}^{\mathrm{G}}$ heterozygous mice, $\sim 96.3 \%$ (734 of 762 ) of $\mathrm{MrgD}^{+}$neurons, marked by GFP expression, coexpressed ing established (Fig. $4 C-F$ ). It was reported previously that Runx1 is expressed in most, if not all, nociceptors at E12.5E14.5, but is extinguished in $\sim 50 \%$ of nociceptors during perinatal and postnatal development (Chen et al., 2006). The simplest interpretation is that Runxl is expressed transiently in immature nociceptors that are fated to become $\mathrm{MrgA3}^{+}$or $\mathrm{MrgB}^{+}{ }^{+}$neurons.

In summary, among $\mathrm{Mrg}^{+}$neurons, persistent Runx1 expression marks the "D" neuronal compartment that expresses $M r g D$, whereas Runx1 is probably expressed transiently in the " $\mathrm{A} / \mathrm{B} / \mathrm{C}$ " compartment that expresses $\operatorname{MrgA}, \operatorname{MrgB}$, and $\operatorname{MrgC}$ subclasses (Fig. 4G). However, it is possible that Runxl might never be expressed in some $\mathrm{MrgA3}^{+}$or $\mathrm{MrgB}^{+}$neurons, thereby nonautonomously controlling the expression of these sensory GPCRs (Fig. 4G). Previous studies show that $\mathrm{Mrg}^{+}$neurons express Ret, but not TrkA (Dong et al., 2001; Zylka et al., 2003). The lack of Runx1 expression in $\mathrm{MrgA} / \mathrm{B} / \mathrm{C}^{+}$neurons implies that Runx1negative cells include both $\operatorname{TrkA}^{+}$neurons (Chen et al., 2006) and Ret $^{+}$neurons.

\section{$\Delta 446 / \Delta 446$ mice}

Runx1 protein contains an N-terminal DNA-binding runt domain, a middle transcriptional activation domain, and a C-terminal peptide VWRPY that is capable of binding the Groucho class transcriptional repressor complex (Fig. 5A). Runx1 therefore can act as either a transcriptional repressor or activator (Durst and Hiebert, 2004). To determine whether Runx1 repressor activity contributes to nociceptor phenotype 
specification, including compartmentalized expression of $\mathrm{Mrg}$ genes, we analyzed $\Delta 446$ mice (Nishimura et al., 2004). $\Delta 446$ encodes a truncated Runx1 protein that lacks the C-terminal repression motif, the VWRPY peptide, but retains the activation domain (Fig. 5A) (Nishimura et al., 2004). In the $\Delta 446$ mutant allele, the DNA sequence that encodes the truncated $\Delta 446$ protein was inserted into the Runx1 locus. As a result, the expression of $\Delta 446$ is under the control of the endogenous Runx1 promoter. Homozygous $\Delta 446 / \Delta 446$ mutant mice survive to adulthood (Nishimura et al., 2004). Total neuron numbers in T12 thoracic DRG, detected by the expression of the panneuronal marker SCG10 (Stein et al., 1988), were not affected by this Runxl mutation, with $1244 \pm 53$ per set of T12 DRG sections in $\Delta 446 / \Delta 446$ mice versus $1276 \pm 35$ in wild-type mice $(p=0.27)$ (see Materials and Methods). The number of DRG neurons that were labeled by the isolectin B4 (IB4) of Griffonia simplicifolia (Silverman and Kruger, 1988) were also not changed, with $645 \pm 15$ per set of T12 DRG sections in $\Delta 446 / \Delta 446$ mice versus $643 \pm 16$ in wild-type mice $(p=0.45)$.

Expression of the truncated $\Delta 446$ protein can still be detected by the anti-Runx1 antibody (Fig. 5B). Double staining of $\Delta 446$ and IB4 in T12 thoracic DRG revealed that $\sim 64.0 \pm 3.6 \%$ of IB $4^{+}$neurons expressed $\Delta 446$ in $\Delta 446 / \Delta 446$ mice, which was not different from $65.4 \pm 2.3 \%$ of $\mathrm{IB} 4^{+}$neurons that expressed the fulllength Runx1 protein in wild-type mice $(p=0.18)$. The percentages of $\Delta 446^{+}$or Runx ${ }^{+}$neurons that were labeled by IB4 were also comparable, with $50.3 \pm 6.9 \%$ in $\Delta 446 / \Delta 446$ mice versus $46.4 \pm 2.7 \%$ in wild-type mice $(p=0.15)$. These data suggest that deletion of the $\mathrm{C}$-terminal repression domain affects neither neuronal survival nor Runxl expression.

Runx1 is required to suppress TrkA and the precursor gene encoding the $\alpha$-CGRP protein in prospective nonpeptidergic neurons (marked by the staining of IB4), as indicated by the derepression of these two genes in $R u n \times 1^{-1-}(W n t 1)$ mice (Chen et al., 2006; Yoshikawa et al., 2007). Expression of TrkA and $\alpha$-CGRP, however, was not expanded in IB4 ${ }^{+}$neurons in $\Delta 446 /$ $\Delta 446$ mice (supplemental Fig. 1, available at www.jneurosci.org as supplemental material). These data suggest that the $\mathrm{C}$-terminal repression domain is not involved with Runx1-mediated suppression of TrkA and $\alpha$-CGRP.

Expression of a set of ion channels and receptors, which is eliminated in conditional Runx1 null mice (Chen et al., 2006), was also not affected in $\Delta 446 / \Delta 446$ mice, including TRP channels (TRPA1, TRPM8, and TRPC3), the ATP-gated channel $\mathrm{P}_{2} \mathrm{X}_{3}$, the sodium channel (SNS2/Nav1.9), and the GDNF receptor Ret (supplemental Figs. 1, 2, available at www.jneurosci.org as supplemental material), implying that Runx1-mediated activation of these nociceptive molecules does not operate through the C-terminal repression domain.
Expansion of $\mathrm{Mrg} A / \mathrm{B} / \mathrm{C}$ gene expression in $\Delta 446 / \Delta 446$ mice

We next examined the expression of $M r g$ genes in $\Delta 446 / \Delta 446$ mice. We found that the expression of class A, B and C Mrg genes was dramatically expanded in adult thoracic DRG of $\Delta 446 / \Delta 446$ homozygous mice, including $M r g A 2-A 7, M r g B 4, M r g B 5$, and $\mathrm{MrgC11}$ (Fig. 6A) (data not shown). The percentage of $\mathrm{MrgA3}^{+}$ neurons in P30 T12 thoracic DRG increased from $4.2 \pm 0.6$ in wild-type mice to $30.1 \pm 1.5$ in $\Delta 446 / \Delta 446$ mice, a 7.2 -fold increase $(p<0.0006)$. Similarly, the percentage of $\mathrm{MrgA4}^{+}$neurons increased from $4.0 \pm 0.1-28.0 \pm 3.0$, a 7.0-fold increase $(p<0.003)$, the percentage of $\mathrm{MrgB}^{+}$neurons increased from $2.9 \pm 0.8-19.4 \pm 1.7$, a 6.7 -fold increase $(p<0.004)$, and the percentage of $\mathrm{MrgCl1}^{+}$neurons increased from $4.2 \pm 0.6-$ $32.3 \pm 1.2(p<0.0002)$ (Fig. $6 B)$. An expansion of $M r g A 3$ and $\mathrm{MrgB} 4$ expression was also observed in lumbar DRG (supplemental Fig. 3, available at www.jneurosci.org as supplemental material). In contrast, we did not observe increased expression of $\operatorname{MrgD}$, the most abundantly expressed family member. In fact, the percentage of $\mathrm{MrgD}^{+}$neurons was slightly but significantly reduced, from $31.1 \pm 1.4$ in wild-type mice to $23.9 \pm 0.4$ in $\Delta 446 / \Delta 446$ mice $(p<0.005)$ (Fig. $6 A, B)$. These data suggest that, during removal of the Runxl repressor domain, there is a selective expansion of neurons that express $M r g A / B / C$ genes.

We next determined when the derepression of $M r g A 3, M r g B 4$ and $\mathrm{MrgC11}$ expression was established, by examining their ex- 
A
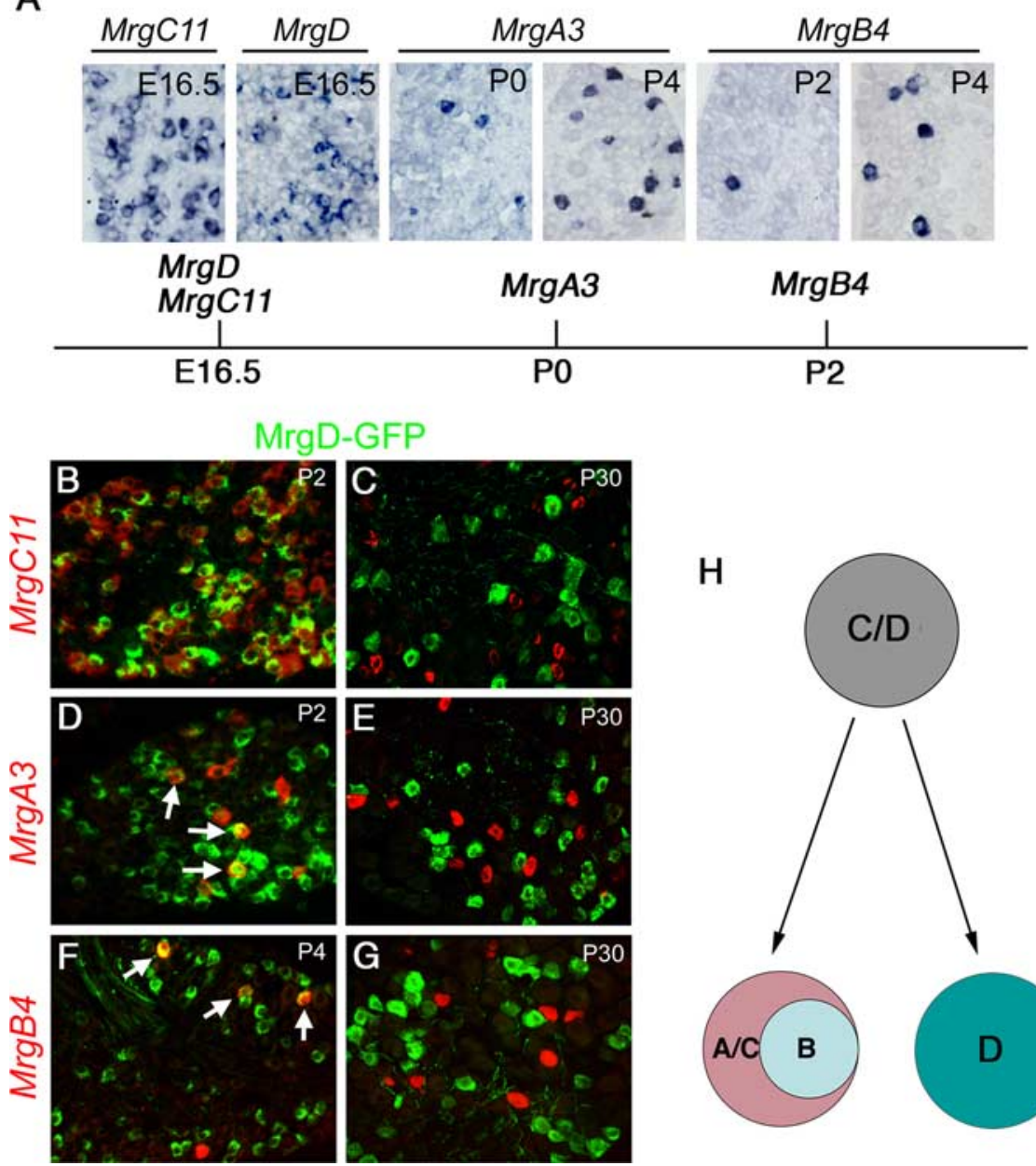

Figure 3. Progressive segregation of $M r g$ compartments. $A$, In situ hybridizations on sections through $T 12$ thoracic wild-type DRG at indicated stages and the schematics for the onset of expression of Mrg genes. $\boldsymbol{B}-\mathbf{G}$, Double staining of GFP protein (green) and Mrg mRNA (red) on sections through thoracic DRG at various stages of $M r g D^{G F P /+}$ heterozygous mice. $\boldsymbol{H}$, Schematics for progressive compartmental segregation of $\mathrm{Mrg}$ gene expression.

pression at multiple developmental stages. In wild-type mice, expression of $\mathrm{MrgA3}$ and $\mathrm{MrgB} 4$ started at $\mathrm{P} 0$ and $\mathrm{P} 2$, respectively, and reached peak levels at approximately P4 (Fig. 6C). In $\Delta 446 / \Delta 446$ mice, onset of $M r g A 3$ and $M r g B 4$ expression was also established at P0 and P2, respectively (Fig. 6C). Expansion of $\mathrm{MrgA} 3$ expression occurred from $\mathrm{P} 2$ to beyond P7, and from $\mathrm{P} 4$ to beyond $\mathrm{P} 7$ for $\mathrm{MrgB} 4$ (Fig. 6C), implying a progressive activation of these GPCR genes. The lack of precocious expression in $\Delta 446 / \Delta 446$ mice also suggests that the late onset of $M r g A 3$ and $\mathrm{MrgB4}$ expression in wild-type mice is not attributable to Runx1mediated repression at embryonic stages. Instead, the activator activity for these GPCR genes is established progressively during neonatal development.

In wild-type mice, $\mathrm{MrgCl1}$ expression is extinguished from $\mathrm{MrgD}^{+}$neurons from P2 to adulthood (Fig. 3). In $\Delta 446 / \Delta 446$ mice, the numbers of $\mathrm{MrgCl1}^{+}$neurons in T12 thoracic DRG did not exhibit gross reduction at stages from P2 to P7 to P30 (Fig. $6 C$ ), implying that Runx1 repression domain is required for postnatal extinguishment of $\mathrm{MrgCl1}$ expression (see also below).

Expansion of $M r g A / B / C$ expression in $\Delta 446 / \Delta 446$ mice is confined to the $\mathrm{IB}^{+}{ }^{+} \mathrm{MrgD}^{+}$neuronal compartment

We next asked which population of neurons shows derepression of these GPCR genes in $\Delta 446 / \Delta 446$ mice. In wild-type thoracic
DRG, $\mathrm{MrgA3}$ and $\mathrm{MrgC11}$ were expressed in both $\mathrm{IB}^{+}$and IB4- neurons (Fig. $7 A, E$, arrows vs arrowheads), whereas MrgB4 (Fig. 7C) and $M r g D$ (Dong et al., 2001) are expressed exclusively in IB4 ${ }^{+}$ neurons. In $\Delta 446 / \Delta 446$ homozygous mice, double staining of IB4 and $\mathrm{Mrg}$ mRNAs showed that expansion of $\mathrm{MrgA3}, \mathrm{MrgB} 4$ and $\mathrm{MrgCl1}$ expression was confined to $\mathrm{IB} 4{ }^{+}$neurons (Fig. $7 B, D, F$ ). The percentage of IB4 ${ }^{+}$neurons expressing $\mathrm{MrgA} 3$ increased from $8.2 \pm 1.4$ in wild-type mice to $74.7 \pm 1.2$ in $\Delta 446 / \Delta 446$ mice $(p<$ 0.0001 ), that of $\mathrm{MrgB} 4^{+}$neurons increased from $6.9 \pm 1.2-37.4 \pm 8.0$ in $\Delta 446 / \Delta 446$ mice $(p<0.02)$, and that of $\mathrm{MrgCl1}^{+}$ neurons increased from $9.7 \pm 1.2-81.4 \pm$ $3.5(p<0.02)$ (Fig. 7G). However, the numbers of $\mathrm{MrgA3}^{+}, \mathrm{MrgA4}^{+}$, or $\mathrm{MrgCl1}^{+}$neurons in the IB4- compartment were not significantly changed (data not shown). Expansion of MrgA3 and $\mathrm{MrgB4}$ expression in lumbar DRG was also confined to IB4 ${ }^{+}$neurons (supplemental Fig. 3, available at www.jneurosci.org as supplemental material). The percentage of $\mathrm{MrgD}^{+}$neurons in T12 thoracic IB4 ${ }^{+}$neuronal population, however, is slightly but significantly reduced, from $81.6 \pm 1.0$ in P30 wild-type mice to $68.5 \pm 1.7$ in $\Delta 446 /$ $\Delta 446$ mice $(p<0.005)$ (Fig. $7 G)$.

In wild-type DRG, the majority of IB4 ${ }^{+}$ neurons express $\mathrm{MrgD}$, and these $\mathrm{MrgD}{ }^{+}$ neurons normally do not coexpress $\mathrm{MrgA3}$, $\mathrm{MrgB} 4$ or $\mathrm{MrgC11}$ (Fig. 2) (Zylka et al., 2003). In adult $\Delta 446 / \Delta 446$ mice, nearly all $\mathrm{MrgD}^{+}$neurons in thoracic DRG coexpressed $\mathrm{MrgA3}$ (Fig. 7H) and $\mathrm{MrgA4}$ (data not shown). Similarly, a portion of $M r g D^{+}$

neurons coexpressed $\mathrm{MrgB} 4$ (Fig. 7I). In addition, because $81.4 \%$ and $68.5 \%$ of $\mathrm{IB}^{+}{ }^{+}$neurons express $\mathrm{MrgCl1}$ and $\mathrm{MrgD}$, respectively, we concluded that at least $49.9 \%[81.4-(100-68.5)=49.9]$ of IB4 ${ }^{+}$neurons coexpress $\mathrm{MrgC11}$ and $\mathrm{MrgD}$ in adult $\Delta 446 /$ $\Delta 446$ mice. These results suggest that Runx1 actively suppresses the expression of $\mathrm{MrgA} / \mathrm{B} / \mathrm{C}$ genes in $\mathrm{MrgD}{ }^{+}$neurons. However, we noted that a small number of $\mathrm{MrgA3}^{+}$or $\mathrm{MrgB}^{+}$cells lacked $M r g D$ expression in $\Delta 446 / \Delta 446$ mice (Fig. $7 H, I$, arrowheads). The simplest interpretation is that in $\Delta 446 / \Delta 446$ mice, $M r g D$ expression is not expanded into the prospective " $\mathrm{A} / \mathrm{B} / \mathrm{C}$ " compartment that normally lack persistent Runx1 expression.

In summary, removal of the C-terminal Runx1 repression domain leads to a unidirectional expansion of $\mathrm{MrgA} / \mathrm{B} / \mathrm{C}$ genes into the "D" neuronal compartment.

\section{Discussion}

Mechanism of compartmentalized expression of Mrg class sensory GPCRs

Our studies suggest a model that leads to compartmentalized expression of Mrg genes. This model contains two key components. First, Runx1 is initially expressed in most embryonic nociceptors at E12.5-E14.5, but is extinguished in $\sim 50 \%$ of cells during perinatal/postnatal development (Chen et al., 2006), leading to the creation of Runx $1^{+}$and Runx $1^{-}$neuronal compart- 


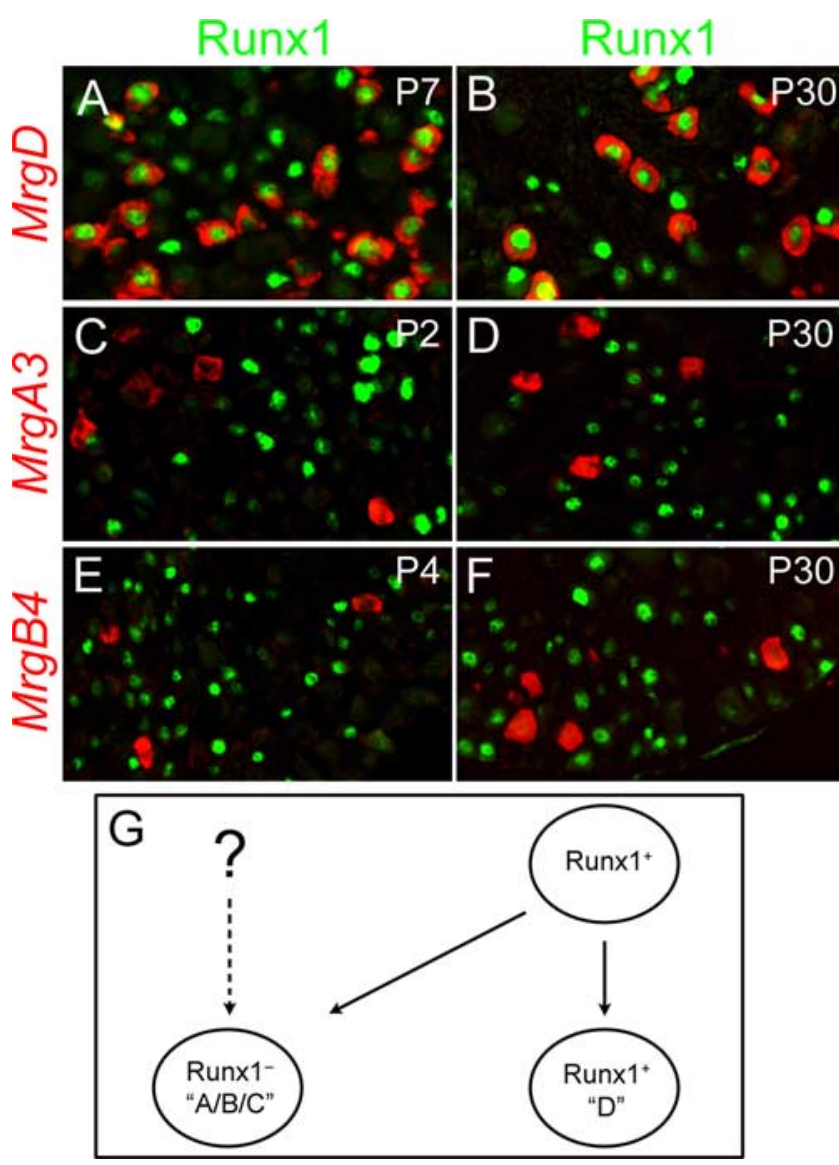

Figure 4. Dynamic Runx1 expression marks distinct Mrg compartments. A-F, Double staining of Runx1 protein (green) and Mrg mRNAs (red) on sections through thoracic wild-type DRG at various stages. $\mathbf{G}$, Schematics for the origin of Mrg compartments. Runx 1 expression in immature $\mathrm{Mrg} A / \mathrm{B} / \mathrm{C}^{+}$neurons is inferred from the fact that Runx1 is expressed in most, if not all, $\mathrm{TrkA}^{+}$neurons at early embryonic stages (Chen et al., 2006), and TrkA signaling is required for the expression of most Mrg genes (Luo et al., 2007). However, it remains a possibility that Runx1 is never expressed in some $\mathrm{MrgA} / \mathrm{B} / \mathrm{C}^{+}$neurons (the dashed line).

ments. Second, different Mrg family members exhibit different responses to Runx1-mediated repression. Runx1 is initially required for the expression of all $\mathrm{Mrg}$ genes, but at an undefined developmental stage Runxl becomes a repressor of $M r g A / B / C$. Accordingly, expression of $M r g A / B / C$ is confined to the Runx ${ }^{-}$ "A/B/C" compartment, and is actively suppressed in the Runx ${ }^{+}$ " $D$ " compartment. During removal of the Runx1 repressor domain in $\Delta 446 / \Delta 446$ mice, the truncated Runxl protein is converted into an activator, leading to a dramatic expansion of $\mathrm{MrgA}$ and $M r g B$ expression in the "D" compartment. The truncated $\Delta 446$ protein is required for the expansion because a null mutation in $R u n \times 1^{-1-}(W n t 1)$ mice leads to a loss, rather than an expansion, of $\mathrm{MrgA}$ and $\mathrm{MrgB}$ expression. $\mathrm{MrgC11}$ is initially expressed in the "D" compartment. Subsequent extinguishment of $\mathrm{MrgC11}$ expression in this compartment relies on Runx1mediated repression. Expression of $M r g D$, however, is essentially insensitive to Runx1-mediated repression, thereby allowing sustained $M r g D$ expression in the Runx1 ${ }^{+}$" $D$ " compartment. In summary, the selective extinguishment of Runx 1 is critical for the establishment of the "A/B/C" compartment (by avoiding Runx1mediated suppression of $M r g A / B / C$ genes at late developmental stages), whereas persistent Runx1 expression allows a singular $M r g D$ expression in the " $\mathrm{D}$ " compartment (by actively suppressing $M r g A / B / C$ expression and possibly maintaining $M r g D$ expression).

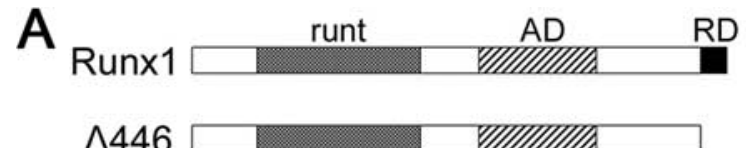

B

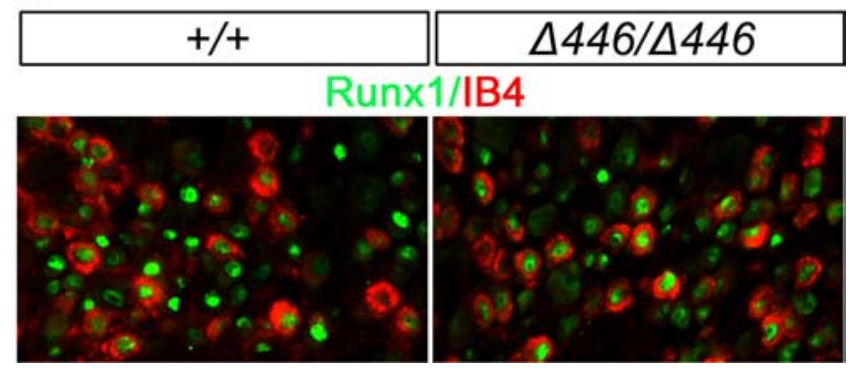

Figure 5. Sensory neuron development in $\Delta 446 / \Delta 446$ mice. $A$, Schematics for full-length Runx1 protein and the truncated $\Delta 446$ protein. The wild-type Runx1 protein ("Runx1") contains the DNA-binding motif "runt," the activation domain "AD," and the C-terminal repression domain "RD." $\Delta 446$ is a truncated Runx1 protein that lacks the RD. $B$, Double staining of IB4 (red) and full-length or truncated Runx1 protein (green) on sections through T12 thoracic DRG of wild-type and $\Delta 446 / \Delta 446$ mice.

A few outstanding issues remain to be solved. First, Runx1 protein is not detected in $\mathrm{MrgA3}^{+}$or $\mathrm{MrgB}^{+}{ }^{+}$neurons at neonatal stages, raising the question about whether Runx1 indirectly or even non-autonomously controls the expression of these GPCR genes. Second, the signal that is responsible for Runx1 extinguishment in the "A/B/C" compartment is unknown. Third, it should be noted that in rat DRG, MrgA and $M r g D$ gene expression overlaps extensively (Zylka et al., 2003), mimicking the expression pattern present in $\Delta 446 / \Delta 446$ mice. The mechanism for species-specific expression pattern is unclear. One attractive possibility is that the rat $M r g A$ promoter loses the capacity to bind to the Runx1 repressor complex, leading to a concurrent Runx1mediated activation of $M r g A$ and $M r g D$ genes.

\section{Runx1 uses distinct pathways to suppress gene expression in nociceptors}

Runx1 is required to suppress several peptidergic neuron markers in $\mathrm{IB}^{+}{ }^{+}$nonpeptidergic nociceptors, including TrkA and CGRP (Chen et al., 2006; Yoshikawa et al., 2007). Here we found that Runxl also actively suppresses $M r g A / B / C$ genes in these neurons. Interestingly, Runx1 uses distinct mechanisms to suppress these two categories of genes. Runx1-mediated suppression of $M r g A / B / C$, but not $\operatorname{Trk} A / C G R P$, is dependent on the C-terminal repression domain that is known to interact with the Grouchorepressor complex (Durst and Hiebert, 2004; Nishimura et al., 2004). Removal of this repression domain in $\Delta 446 / \Delta 446$ mice leads to a derepression of $M r g A / B / C$ (Figs. 6, 7), without causing a concurrent derepression of TrkA/CGRP in IB $4{ }^{+}$neurons (supplemental Fig. 1, available at www.jneurosci.org as supplemental material). In the immune system, Runxl is able to use multiple repression domains to suppress $\mathrm{T}$ cell receptor expression (Durst and Hiebert, 2004; Telfer et al., 2004). Runx1 could in principle use a different repression domain to suppress TrkA/CGRP. Alternatively, Runx1 may activate a downstream pathway that indirectly suppresses peptidergic neuron markers. A support for the latter scenario is the finding that Ret-mediated signaling is required for postnatal suppression of TrkA in IB $4^{+}$neurons (Luo et al., 2007). Accordingly, the loss of Ret expression after conditional Runxl knock-out may explain the derepression of TrkA 
A
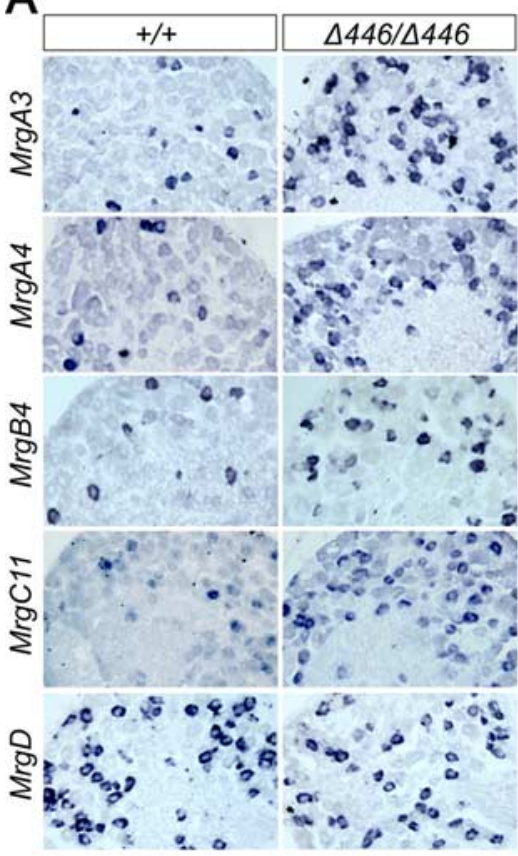

B
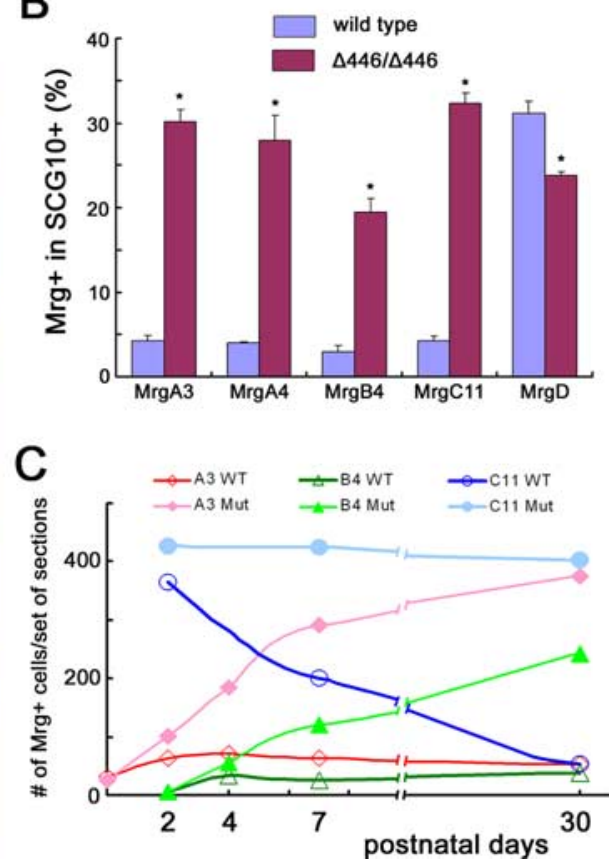

Figure 6. Expansion of $M r g$ genes in $\Delta 446 / \Delta 446$ mice. $A$, In situ hybridizations with indicated $M r g$ probes on sections through T12 thoracic DRG of P30 wild-type and $\Delta 446 / \Delta 446$ mice. $B$, Percentages of $\mathrm{Mrg}^{+}$neurons in T12 thoracic DRG of P30 wild-type and $\Delta 446 / \Delta 446$ mice $\left({ }^{*} p<0.005\right) . C, M r g A 3^{+}, M_{r g B 4}{ }^{+}$, and $M r g C 11^{+}$neuron numbers in $\mathrm{T} 12$ thoracic DRG of wild-type and $\Delta 446 / \Delta 446$ mice at multiple developmental stages. Six adjacent sets of sections were prepared from each DRG, and numbers of positive neurons in one of the six sets were presented.
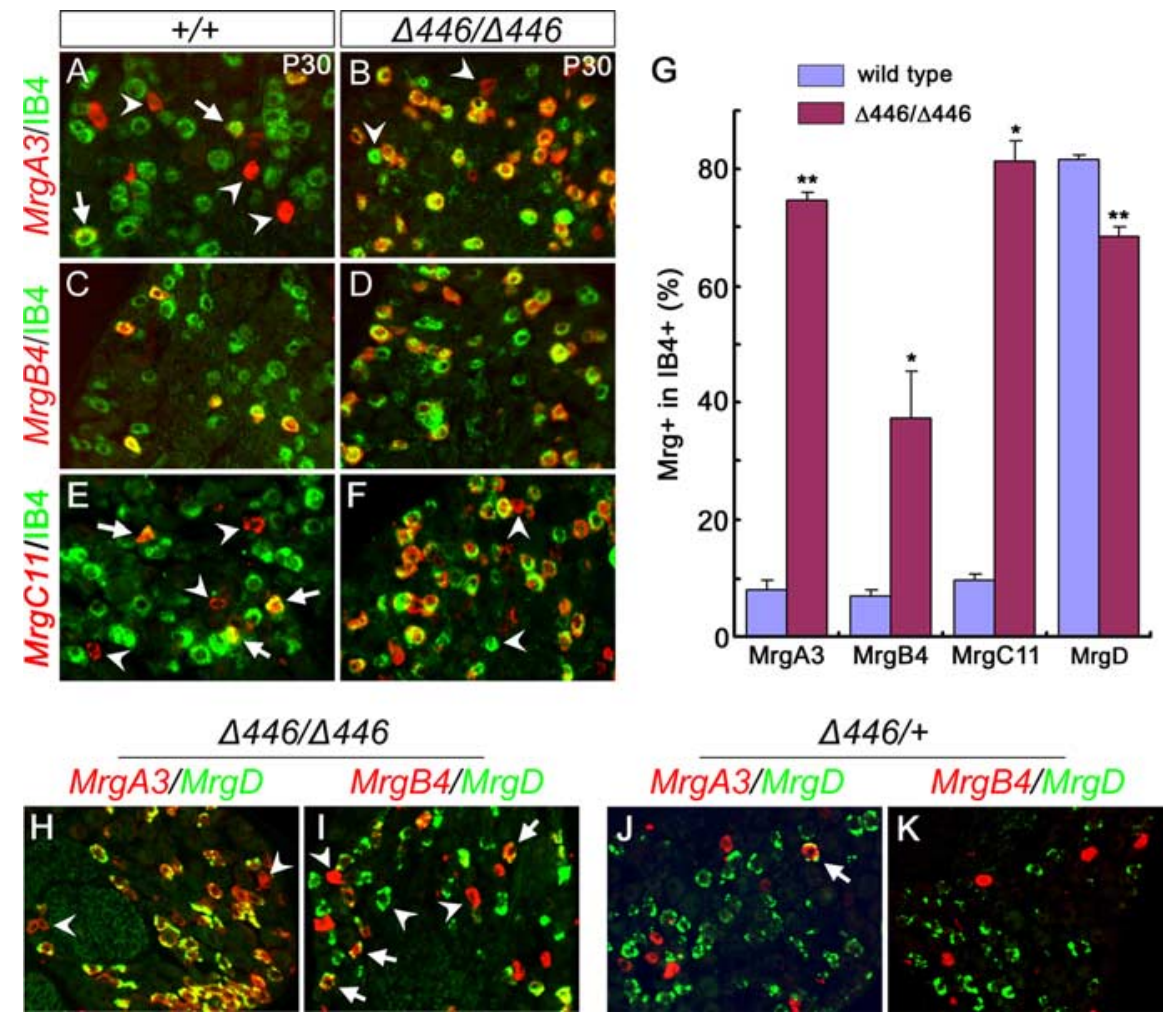

Figure 7. Expansion of $M r g A 3, M r g B 4$, and $M r g C 11$ expression in IB4 ${ }^{+} ; M r g D^{+}$neurons in $\Delta 446 / \Delta 446$ mice. $A-F$, Double staining of IB4 ( $\boldsymbol{A}-\boldsymbol{F}$, green) and $\operatorname{Mrg} A 3 \mathrm{mRNA}(\boldsymbol{A}, \boldsymbol{B}$, red), $\operatorname{Mrg} B 4 \mathrm{mRNA}(\boldsymbol{C}, \boldsymbol{D}$, red) or $\operatorname{Mrg} C 11 \mathrm{mRNA}(\boldsymbol{E}, \boldsymbol{F}$, red) on sections through thoracic DRG of P30 wild-type and $\triangle 446 / \Delta 446$ mice. G, The percentage of IB4 ${ }^{+}$neurons that express MrgA3, MrgB4, Mrg C11, or MrgD in T12 thoracic DRG of P30 wild-type and $\Delta 446 / \Delta 446$ homozygous mice $\left({ }^{*} p<0.02 ;{ }^{* *} p<0.005\right)$. $\boldsymbol{H}-\boldsymbol{K}$, Double color in situ hybridization on sections through T12 thoracic DRG of P30 $\Delta 446 / \Delta 446$ homozygous mice $(H, I)$ and P30 $\Delta 446 /+$ heterozygous mice $(\boldsymbol{J}, \boldsymbol{K})$.

and CGRP in Runx1 $1^{-1-}($ Wnt1) mice (Chen et al., 2006; Yoshikawa et al., 2007), whereas a normal expression of Ret in $\Delta 446 / \Delta 446$ mice (supplemental Fig. 1 , available at www.jneurosci.org as supplemental material) may explain the lack of TrkA derepression. Regardless, Runx1 operates through distinct pathways to suppress peptidergic differentiation and $M r g A / B / C$ expression.

\section{Progressive specification of sensory neuron subtypes}

Our studies, combined with a series of recent studies, suggest that specification of sensory subtypes is progressively established during perinatal and postnatal development. Most embryonic nociceptors (and thermoceptors) initially express both Runxl and TrkA (Chen et al., 2006). To our knowledge, there are no known molecular markers that are able to divide TrkA ${ }^{+}$ neurons into distinct subgroups at E12.5. It is from E14.5 to postnatal stages that nociceptors are progressively segregated into Ret $^{+}, \operatorname{TrkA}^{+}$and Ret ${ }^{+} ; \operatorname{TrkA}{ }^{+}$subclasses, with persistent Runxl expression is confined to a portion of Ret $^{+}$neurons (Bennett et al., 1996, 1998; Molliver et al., 1997; Chen et al., 2006). Nociceptors that express distinct profiles of TRP class thermal receptors also emerge during perinatal/postnatal development (Hjerling-Leffler et al., 2007). Here we further found that $\mathrm{Mrg}^{+}$ sensory neurons initially coexpress $\mathrm{MrgD}$ and $\mathrm{MrgCl1}$ at embryonic stages. During postnatal development, future $\mathrm{MrgC11}{ }^{+}$ neurons extinguish $\operatorname{MrgD}$ and activate $M r g A$ and/or $M r g B$ genes. Conversely, future $\mathrm{MrgD}^{+}$neurons switch off $\mathrm{MrgCl1}$, leading to a mutually exclusive expression of $M r g A / B / C$ and $M r g D$.

Intriguingly, $\mathrm{MrgD}^{+}$afferents innervate skin epidermis (Zylka et al., 2005), whereas $\mathrm{MrgB}^{+}$afferents innervate exclusively the hairy skin (Liu et al., 2007). Such topographically distinct innervation raises the hypothesis that segregation of $\mathrm{MrgD}^{+}$ and $\mathrm{MrgB}^{+}$nociceptors might partly depend on specific target-derived signals. Indeed, Ret signaling is required for the expression of MrgB4 (and MrgA3), but not $M r g D$ (Luo et al., 2007). Hair follicles also release other signaling molecules, such as bone morphological proteins or BMPs (Blanpain and Fuchs, 2006). Indeed, a conditional knock-out of Smad4, encoding a key component of BMP-mediated signaling (Yang et al., 2002), is required selectively for the expression of MrgB4 (supplemental Fig. 4, available at www.jneurosci. org as supplemental material). Future studies will be directed to investigate how 
target-derived signals interface with intrinsic factors, such as Runxl, in generating sensory cell diversity.

\section{References}

Agarwal N, Offermanns S, Kuner R (2004) Conditional gene deletion in primary nociceptive neurons of trigeminal ganglia and dorsal root ganglia. Genesis 38:122-129.

Bennett DL, Averill S, Clary DO, Priestley JV, McMahon SB (1996) Postnatal changes in the expression of the trkA high-affinity NGF receptor in primary sensory neurons. Eur J Neurosci 8:2204-2208.

Bennett DL, Michael GJ, Ramachandran N, Munson JB, Averill S, Yan Q, McMahon SB, Priestley JV (1998) A distinct subgroup of small DRG cells express GDNF receptor components and GDNF is protective for these neurons after nerve injury. J Neurosci 18:3059-3072.

Blanpain C, Fuchs E (2006) Epidermal stem cells of the skin. Annu Rev Cell Dev Biol 22:339-373.

Burstein ES, Ott TR, Feddock M, Ma JN, Fuhs S, Wong S, Schiffer HH, Brann MR, Nash NR (2006) Characterization of the Mas-related gene family: structural and functional conservation of human and rhesus MrgX receptors. Br J Pharmacol 147:73-82.

Cai Q, Jiang J, Chen T, Hong Y (2007) Sensory neuron-specific receptor agonist BAM8-22 inhibits the development and expression of tolerance to morphine in rats. Behav Brain Res 178:154-159.

Chen CL, Broom DC, Liu Y, de Nooij JC, Li Z, Cen C, Samad OA, Jessell TM, Woolf CJ, Ma Q (2006) Runxl determines nociceptive sensory neuron phenotype and is required for thermal and neuropathic pain. Neuron 49:365-377.

Choi SS, Lahn BT (2003) Adaptive evolution of MRG, a neuron-specific gene family implicated in nociception. Genome Res 13:2252-2259.

Crozier RA, Ajit SK, Kaftan EJ, Pausch MH (2007) MrgD activation inhibits $\mathrm{KCNQ} / \mathrm{M}$-currents and contributes to enhanced neuronal excitability. J Neurosci 27:4492-4496.

Dong X, Han S, Zylka MJ, Simon MI, Anderson DJ (2001) A diverse family of GPCRs expressed in specific subsets of nociceptive sensory neurons. Cell 106:619-632.

Durst KL, Hiebert SW (2004) Role of RUNX family members in transcriptional repression and gene silencing. Oncogene 23:4220-4224.

Grazzini E, Puma C, Roy MO, Yu XH, O’Donnell D, Schmidt R, Dautrey S, Ducharme J, Perkins M, Panetta R, Laird JM, Ahmad S, Lembo PM (2004) Sensory neuron-specific receptor activation elicits central and peripheral nociceptive effects in rats. Proc Natl Acad Sci USA 101:7175-7180.

Growney JD, Shigematsu H, Li Z, Lee BH, Adelsperger J, Rowan R, Curley DP, Kutok JL, Akashi K, Williams IR, Speck NA, Gilliland DG (2005) Loss of Runx1 perturbs adult hematopoiesis and is associated with a myeloproliferative phenotype. Blood 106:494-504.

Hjerling-Leffler J, Alqatari M, Ernfors P, Koltzenburg M (2007) Emergence of functional sensory subtypes as defined by transient receptor potential channel expression. J Neurosci 27:2435-2443.

Jiang X, Rowitch DH, Soriano P, McMahon AP, Sucov HM (2000) Fate of the mammalian cardiac neural crest. Development 127:1607-1616.

Kramer I, Sigrist M, de Nooij JC, Taniuchi I, Jessell TM, Arber S (2006) A role for Runx transcription factor signaling in dorsal root ganglion sensory neuron diversification. Neuron 49:379-393.

Lembo PM, Grazzini E, Groblewski T, O’Donnell D, Roy MO, Zhang J, Hoffert C, Cao J, Schmidt R, Pelletier M, Labarre M, Gosselin M, Fortin Y, Banville D, Shen SH, Strom P, Payza K, Dray A, Walker P, Ahmad S
(2002) Proenkephalin A gene products activate a new family of sensory neuron-specific GPCRs. Nat Neurosci 5:201-209.

Levanon D, Bettoun D, Harris-Cerruti C, Woolf E, Negreanu V, Eilam R, Bernstein Y, Goldenberg D, Xiao C, Fliegauf M, Kremer E, Otto F, Brenner O, Lev-Tov A, Groner Y (2002) The Runx3 transcription factor regulates development and survival of TrkC dorsal root ganglia neurons. EMBO J 21:3454-3463.

Liu Q, Vrontou S, Rice FL, Zylka MJ, Dong X, Anderson DJ (2007) Molecular genetic visualization of a rare subset of unmyelinated sensory neurons that may detect gentle touch. Nat Neurosci 10:946-948.

Luo W, Wickramasinghe SR, Savitt JM, Griffin JW, Dawson TM, Ginty DD (2007) A Hierarchical NGF signaling cascade controls Ret-dependent and Ret-independent events during development of nonpeptidergic DRG neurons. Neuron 54:739-754.

Marmigere F, Montelius A, Wegner M, Groner Y, Reichardt LF, Ernfors P (2006) The Runx1/AML1 transcription factor selectively regulates development and survival of TrkA nociceptive sensory neurons. Nat Neurosci 9:180-187.

Molliver DC, Wright DE, Leitner ML, Parsadanian AS, Doster K, Wen D, Yan Q, Snider WD (1997) IB4-binding DRG neurons switch from NGF to GDNF dependence in early postnatal life. Neuron 19:849-861.

Nishimura M, Fukushima-Nakase Y, Fujita Y, Nakao M, Toda S, Kitamura N, Abe T, Okuda T (2004) VWRPY motif-dependent and -independent roles of AML1/Runx1 transcription factor in murine hematopoietic development. Blood 103:562-570.

Silverman JD, Kruger L (1988) Lectin and neuropeptide labeling of separate populations of dorsal root ganglion neurons and associated "nociceptor" thin axons in rat testis and cornea whole-mount preparations. Somatosens Res 5:219-246.

Stein R, Orit S, Anderson DJ (1988) The induction of a neural-specific gene, SCG10, by nerve growth factor in PC12 cells is transcriptional, protein synthesis dependent, and glucocorticoid inhibitable. Dev Biol 127:316-325.

Telfer JC, Hedblom EE, Anderson MK, Laurent MN, Rothenberg EV (2004) Localization of the domains in Runx transcription factors required for the repression of CD4 in thymocytes. J Immunol 172:4359-4370.

Theriault FM, Nuthall HN, Dong Z, Lo R, Barnabe-Heider F, Miller FD, Stifani S (2005) Role for Runx1 in the proliferation and neuronal differentiation of selected progenitor cells in the mammalian nervous system. J Neurosci 25:2050-2061.

Woolf CJ, Ma Q (2007) Nociceptors-noxious stimulus detectors. Neuron 55:353-364.

Yang X, Li C, Herrera PL, Deng CX (2002) Generation of Smad4/Dpc4 conditional knockout mice. Genesis 32:80-81.

Yoshikawa M, Senzaki K, Yokomizo T, Takahashi S, Ozaki S, Shiga T (2007) Runx1 selectively regulates cell fate specification and axonal projections of dorsal root ganglion neurons. Dev Biol 303:663-674.

Zhang L, Taylor N, Xie Y, Ford R, Johnson J, Paulsen JE, Bates B (2005) Cloning and expression of MRG receptors in macaque, mouse, and human. Brain Res Mol Brain Res 133:187-197.

Zhong J, Pevny L, Snider WD (2006) "Runx"ing towards sensory differentiation. Neuron 49:325-327.

Zylka MJ, Dong X, Southwell AL, Anderson DJ (2003) Atypical expansion in mice of the sensory neuron-specific Mrg G protein-coupled receptor family. Proc Natl Acad Sci USA 100:10043-10048.

Zylka MJ, Rice FL, Anderson DJ (2005) Topographically distinct epidermal nociceptive circuits revealed by axonal tracers targeted to Mrgprd. Neuron 45:17-25. 